\title{
STUDY OF COATINGS OBTAINED FROM ALLOY FE-MN-C-B-Si-Ni-Cr
}

\author{
Mykhaylo I. Pashechko', Krzysztof Dziedzic', Marcin Barszcz'
}

1 Faculty of Fundamentals of Technology, Lublin University of Technology, Nadbystrzycka 38 Str., 20-618 Lublin, Poland, e-mail: m.paszeczko@pollub.pl, m.barszcz@pollub.pl

Received: 2016.06.11 Accepted: 2016.07.14 Published: 2016.09.01

\begin{abstract}
Tribological behaviour of coatings obtained from eutectic alloy Fe-Mn-C-B-Si-Ni$\mathrm{Cr}$ was studied. The coatings were obtained by the method of gas metal arc welding (GMA) with use of powder wire. GMA welding method is widely used for the regeneration of machine parts. Eutectic Fe-Mn-C-B-Si-Ni-Cr alloys can be used to obtain high quality coatings resistant to wear and corrosion. Pin-on-disk dry sliding wear tests at sliding speeds $0.4 \mathrm{~m} / \mathrm{s}$ and under load $10 \mathrm{MPa}$ were conducted for pin specimens. During friction a typical tribological behavior was observed. The mechanism of wear was mechanical-chemical.
\end{abstract}

Keywords: wear, friction, coatings, welding.

\section{INTRODUCTION}

Introduction of structural changes in machines and mechanisms operating in wear conditions with the use of eutectic alloy and other materials for building up wear-resistant coatings makes it possible to increase significantly the resistance of their elements to wear. The $\mathrm{Fe}, \mathrm{Co}, \mathrm{Ni}, \mathrm{Ti}$ - based alloy are most widely used for improvement of materials wear-resistance [12]. Many scientific papers deal with this problem. Alloy based on TiCr-Si [3], Ni-Fe-C-M [4], Fe-C-Cr-Si [2], Fe-CrTi-Nb-V-C [14], Fe-Ti-V-Mo-C [13] are the most widely used in practice. For machine elements, operating in wear conditions, it is very important to investigate the intensity of machine materials wear and also the physicochemical processes taking place on the friction surface in order to improve the resistance of materials to wear $[1,6,9]$.

Using the methods of secondary ions mass spectrometry and Auger spectroscopy it was found in papers that high wear resistance of $\mathrm{Fe}$ $\mathrm{Mn}-\mathrm{C}-\mathrm{B}-\mathrm{Si}-\mathrm{Ni}-\mathrm{Cr}$ eutectic coatings, obtained by electric arc welding (EAW) with use of powder electrodes, is caused by C, B and Si atoms segregation on the friction surface. In this case the non-stoihiometric phases (nanophases) based on
$\mathrm{B}_{2} \mathrm{O}_{3}, \mathrm{SiO}_{2}$ and $\mathrm{C}$ are formed due to tribosynthesis $[7,10]$. Formation of the tribofilm or "secondary structures" on the friction surface promotes the increase of wear-resistance of eutectic alloys and coatings. Researches into the tribofilm or "secondary structures" formation can be carried out using modern methods of spectroscopy $[5,11]$.

Composition of elements for obtaining a multi-phase Fe-Mn-C-B eutectic alloy (wt.\%) is: Fe 85.1-92.5; Mn 1.6-7.6; C 2.6-7.0; B 0.2-3.5 [8-9]. Content of elements in Fe-Mn-C and Fe-B$\mathrm{C}$ eutectic regions is given in Table 1 .

Content of such alloying elements as $\mathrm{Si}, \mathrm{Ni}$, $\mathrm{Cr}$ and other is chosen with account of possibility of getting coatings with eutectic structure resistant to wear, taking into account also their efficiency. The structure of the eutectic layer con-

Table 1. Content of elements in Fe-Mn-C and Fe-B-C eutectic regions [8]

\begin{tabular}{|l|c|c|c|c|}
\hline \multirow{2}{*}{ Alloy } & \multicolumn{4}{|c|}{ Element } \\
\cline { 2 - 5 } & $\begin{array}{c}\mathrm{Fe} \\
\text { (wt. \%) }\end{array}$ & $\begin{array}{c}\mathrm{Mn} \\
\text { (wt. \%) }\end{array}$ & $\begin{array}{c}\mathrm{C} \\
\text { (wt.\%) }\end{array}$ & $\begin{array}{c}\mathrm{B} \\
\text { (wt. \%) }\end{array}$ \\
\hline Fe-Mn-C & $73.3-92.5$ & $3.1-23.8$ & $0.6-6.4$ & $0.6-2.5$ \\
\hline Fe-B-C & $85.1-92.5$ & $1.6-7.6$ & $2.6-7.0$ & $0.2-3.5$ \\
\hline
\end{tabular}


sists of alloyed austenite $\mathrm{Fe}_{\gamma}(\mathrm{Ni}, \mathrm{Cr}$ ) (soft phase), manganese-iron carbide $\mathrm{Fe}_{0,4} \mathrm{Mn}_{3,6} \mathrm{C}$ (strengthening phase) and $\mathrm{Fe}_{2} \mathrm{~B}$ (dispersed phase) [9-10]. To obtain wear-resistant coatings, especially for strengthening and regeneration of the parts of machines and mechanisms, the process of surfacing is often used. Properties of overlays depend not only on the content of powder wires, but also on the technology of surfacing, which can change significantly the structure of the overlay, thus affecting its operation properties.

\section{EXPERIMENTAL}

To obtain coatings the method of gas metal arc welding GMA is used. As a specimen material $\mathrm{S} 235 \mathrm{JR}$ steel is used Table 2. Protective environment is used $\mathrm{CO}_{2}$. The hardness of the coating is 49-62 HRC.

Table 2. Chemical composition of steel S 235 JR

\begin{tabular}{|c|c|c|c|c|c|c|}
\hline \multirow{3}{*}{$\begin{array}{c}\mathrm{S} \\
235\end{array}$} & \multicolumn{6}{|c|}{ Element } \\
\cline { 2 - 7 } & $\mathrm{C}$ & $\mathrm{Mn}$ & $\mathrm{Si}$ & $\mathrm{P}$ & $\mathrm{S}$ & $\mathrm{N}$ \\
JR & $(w t . \%)$ & $(w t . \%)$ & $(w t . \%)$ & $($ wt.\%) & (wt.\%) & (wt.\%) \\
\cline { 2 - 7 } & 0.20 & 1.4 & - & 0.035 & 0.035 & 0.0012 \\
\hline
\end{tabular}

Content of $\mathrm{Si}, \mathrm{Cr}, \mathrm{Ni}$ alloying elements in powder wires is given in Table 3. Specimens for investigation were cut out by electric erosion method.

Investigations for wear-resistance were carried out on a Amsler tribotester. Main friction parameters were as follows:

- type of contact: distributed, flat (in a pin-on disc system),

- the connection of pin-on disc friction pair is created by a rotating disc and sample being pressed onto it (sample shape: 10x10mm square, disc diameter $90 \mathrm{~mm}$, hardness $52 \mathrm{HRC}$ ),

- type of movement: sliding friction (velocity $0.4 \mathrm{~m} / \mathrm{s})$,
- load: $10 \mathrm{MPa}$,

- duration of a single tribological test: 6 hours.

The surface of the coating was examined before and after the tribological tests. In the first stage, the surface was observed under an optical metallographic microscope Nikon Eclipse MA 200. The surface micro geometry profile was examined with profilograph Surtronic 3+. A Scanning electron microscope FEI Quanta 3D FEG with EDAX x-ray microanalyzer and BS 340 Tesla was used for the examination of topography and morphology of the friction surface of the material and counterbodies, as well. The images of the wear scar were recorded in a High Vacuum mode (pressure $<6 \cdot 10^{-4} \mathrm{~Pa}$ ) with $20 \mathrm{kV}$ accelerating voltage and with a SE detection mode. The resolution of the electron beam in the analyzed conditions was $1.2 \mathrm{~nm}$.

\section{RESULTS AND DISCUSSION}

Under exploitation of machines the investigations of wear kinetics of the elements that operate in wear conditions are very important. Wear kinetics of the coatings is shown in Figure 1.

The highest wear resistance has a L-7 sample with a composition of alloying elements 2.46 wt.\% Si, 17.68 wt.\% Ni, 16.24 wt.\% Cr. The average mass loss of samples L-7 after tribological tests with a $10 \mathrm{MPa}$ load and examination time of 6 hours was $125 \mathrm{mg}$ (Fig. 2a). At the same time for L-7, the average mass loss of counterbodies was $228 \mathrm{mg}$. The average wear coefficient was 0.59 .

The character of changes in the eutectic coating after tribological tests was monitored with an optic microscope. As can be seen in presented micrograph (Fig. 3) the surface after friction is relatively smooth with a visible track of mechanical wear (Fig. 2a, b). The roughness $\mathrm{R}_{\mathrm{a}}$ is 0.692 .

Microanalysis of the friction surface by SEM with device EDS allowed us to obtain chemical composition and elements distribution on the

Table 3. Elements content in coatings

\begin{tabular}{|c|c|c|c|c|c|c|c|}
\hline \multirow{2}{*}{$\begin{array}{c}\text { Elements } \\
\text { (wt.\%) }\end{array}$} & \multicolumn{7}{|c|}{ Coating } \\
\hline & L-I & $\mathrm{L}-2$ & L-3 & L-4 & L-5 & L-6 & L-7 \\
\hline $\mathrm{Cr}$ & 10,53 & 10,97 & 16,28 & 13,92 & 15,89 & 15,35 & 16,24 \\
\hline $\mathrm{Si}$ & 2,15 & 2,30 & 2,67 & 2,70 & 2,32 & 1,91 & 2,46 \\
\hline $\mathrm{Ni}$ & 12,42 & 8,36 & 8,25 & 11,00 & 10,50 & 10,21 & 17,68 \\
\hline $\mathrm{Fe}, \mathrm{Mn}, \mathrm{C}, \mathrm{B}$ & \multicolumn{7}{|c|}{ rest } \\
\hline
\end{tabular}




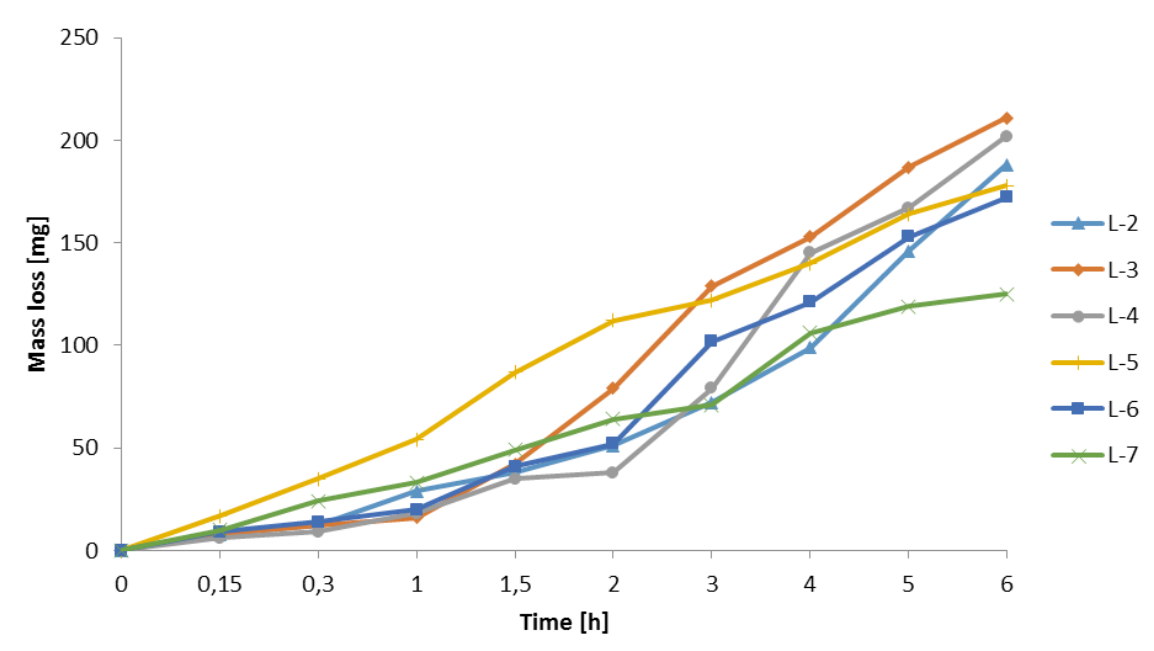

Fig. 1. Wear kinetics of Fe-Mn-C-B-Si-Ni-Cr coating
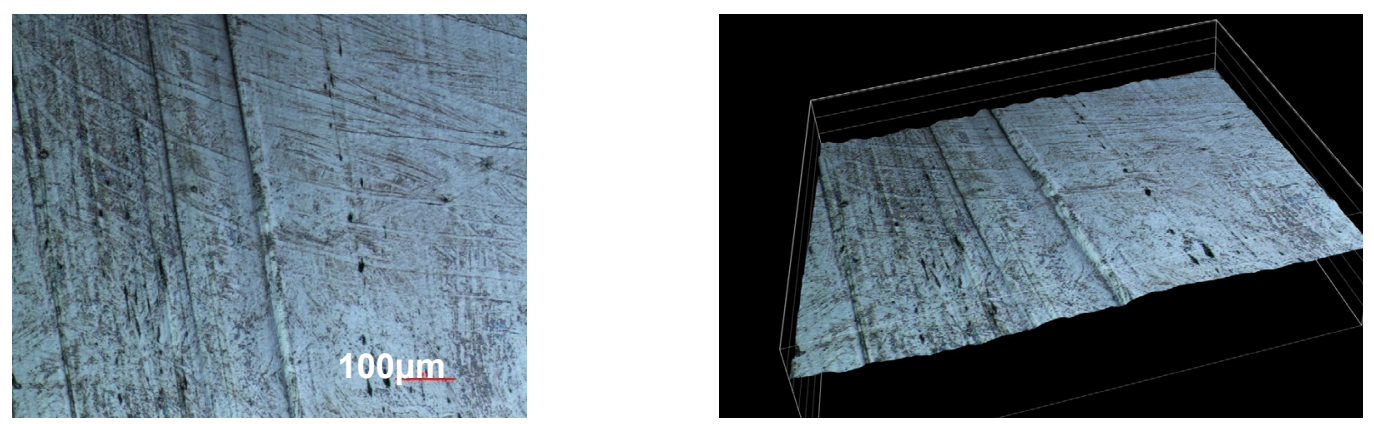

Fig. 2. Metalographic microscope, magnification: x100. Images of wear trace on eutectic alloy surface after friction (left), and topography in 3D perspective (right)

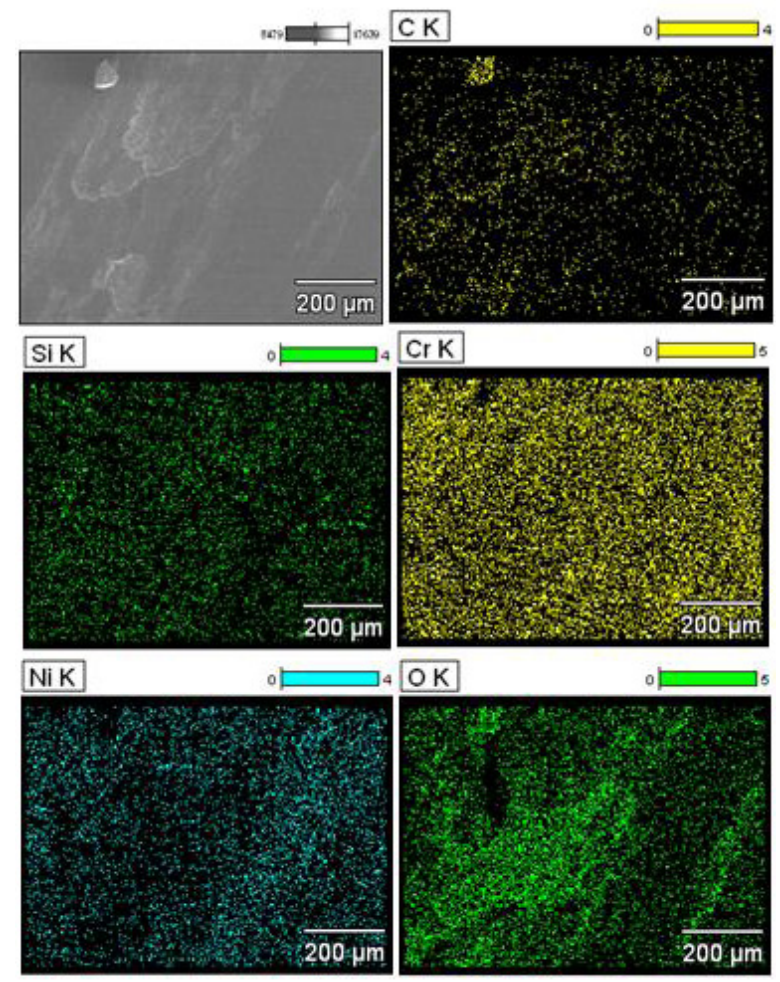

Fig. 3. Distribution of $\mathrm{C}, \mathrm{Cr}, \mathrm{Si}, \mathrm{Ni}, \mathrm{O}$ on the friction surface of eutectic alloy under specific loading of $10 \mathrm{MPa}$ 
Table 4. Distribution of elements on the friction surface

\begin{tabular}{|c|c|c|c|c|c|c|c|c|}
\hline \multirow{4}{*}{ Elements } & \multicolumn{8}{|c|}{ Friction surface } \\
\hline & \multicolumn{8}{|c|}{ Microvolumes } \\
\hline & \multicolumn{2}{|c|}{1} & \multicolumn{2}{|c|}{2} & \multicolumn{2}{|c|}{3} & \multicolumn{2}{|c|}{4} \\
\hline & Wt \% & At $\%$ & Wt \% & At $\%$ & Wt \% & At $\%$ & Wt \% & At $\%$ \\
\hline B & 2,45 & 7,15 & 1,77 & 6,47 & 1,11 & 4,28 & 1,9 & 5,79 \\
\hline C & 7,91 & 20,73 & 4,86 & 16,01 & 5,63 & 19,53 & 7,85 & 21,50 \\
\hline $\mathrm{N}$ & 1,43 & 3,23 & 0,92 & 2,61 & 0,82 & 2,45 & 1 & 2,34 \\
\hline $\mathrm{O}$ & 12,88 & 25,36 & 4,63 & 11,44 & 1,69 & 4,40 & 11,4 & 23,45 \\
\hline $\mathrm{Si}$ & 1,59 & 1,78 & 1,42 & 2,00 & 2,09 & 3,10 & 1,26 & 1,48 \\
\hline$S$ & 0,21 & 0,21 & 0,16 & 0,20 & 0,17 & 0,22 & 0,18 & 0,19 \\
\hline $\mathrm{Cr}$ & 6,99 & 4,24 & 10,16 & 7,73 & 6,7 & 5,37 & 9,15 & 5,79 \\
\hline $\mathrm{Mn}$ & 3,64 & 2,09 & 4,47 & 3,22 & 5,52 & 4,19 & 3,96 & 2,37 \\
\hline $\mathrm{Fe}$ & 53,99 & 30,45 & 59,34 & 42,04 & 62,29 & 46,52 & 55,89 & 32,93 \\
\hline $\mathrm{Ni}$ & 8,89 & 4,77 & 12,27 & 8,27 & 13,98 & 9,93 & 7,41 & 4,16 \\
\hline
\end{tabular}

friction surface. Distribution of elements on the friction surface of eutectic alloy under loading 10 $\mathrm{MPa}$ is presented in Figure 3. Non-uniform distribution of carbon, silicon and oxygen atoms on the friction surface is obtained. The presence of oxygen can testify to formation of oxides that is speaking about the mechanical-chemical mechanism of wear.

Investigations have been also done for microvolumes 1 to 4 shown in Figure 4. The surface after friction has a "flake-layer" composition. The results of EDX analysis recorded at different friction microvolumes of the sample after friction are shown in Table 4.

As it is seen in Table 4 the increase of the content of $\mathrm{C}, \mathrm{O}$ atoms is observed on the friction sur-

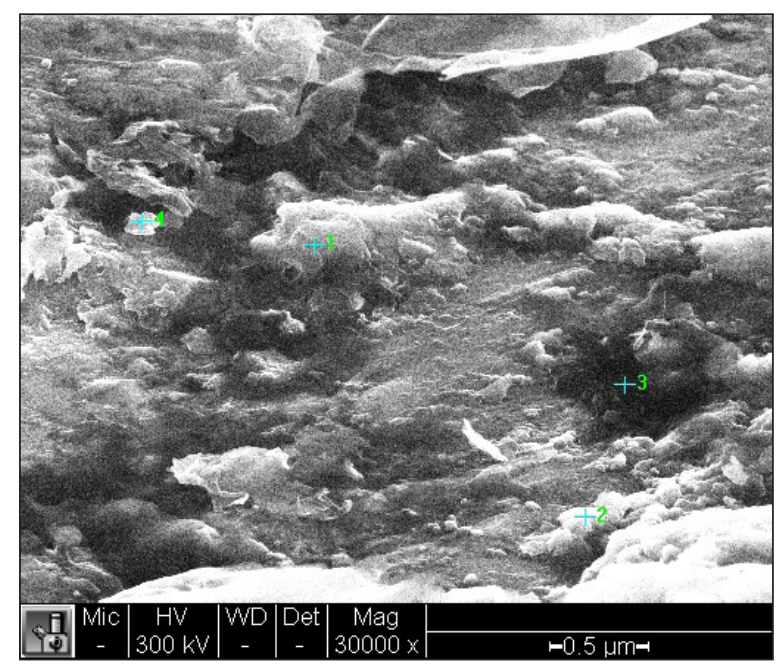

Fig. 4. View of the friction surface face to compare with the initial one (before friction). The content of carbon changes from 5.63 to 7.91 wt \%. in microregions. The content of oxygen changes from 1.69 to $12,88 \mathrm{wt} \%$. in microregions. Silicon content changes from 1.26 to 2.09 wt \%. in microregions. Boron content changes from 1.11 to $2.45 \mathrm{wt} \%$.

As a results of tribosynthesis, non-stoichiometric phases (nano-phases) $\mathrm{B}_{2} \mathrm{O}_{3}, \mathrm{SiO}_{2}$ and $\mathrm{C}$ can be formed. A similar wear mechanism was revealed during friction of eutectic Fe-Mn-C-B$\mathrm{Si}-\mathrm{Ni}-\mathrm{Cr}$ alloys, obtained by the method of electric arc welding with application of powder electrodes [6].

\section{CONCLUSIONS}

Multi-component Fe-Mn-C-B-Si-Cr-Ni eutectic alloys allow us to obtain on the surface of $\mathrm{S}$ $235 \mathrm{JR}$ steel the wear-resistant coatings by the gas metal arc welding (GMA), using powder wires.

Using scanning electron microscopy with EDS device the increase of the content of $\mathrm{C}, \mathrm{O}$ on the eutectic coating friction surface under specific loading of $10 \mathrm{MPa}$ has been found. It has been revealed that under friction the mechanicalchemical mechanism of wear takes place. As a result of tribosynthesis non-stoichiometric phases (nano-phases) $\mathrm{B}_{2} \mathrm{O}_{3}, \mathrm{SiO}_{2}$ and $\mathrm{C}$ can be formed. The next step of research should be a XPS and SIMS investigations to confirm what chemical composition are formed on friction surface. 


\section{REFERENCES}

1. Fox-Rabinovich G.S., Totten G.E., Self-organization during friction, Advance Surface Engineered Materials and Systems Design, CRC Taylor and Francis Group, Boca Raton, 2006.

2. Granat K., Multi-component wear-resistant Fe-C$\mathrm{Cr}-\mathrm{Si}$ alloys used for production of moulding and overlayers, Wrocław 2005.

3. Hadad M., Bandyopadhyay P., Michler J., Lesage J., Tribological behaviour of thermally sprayed Ti-Cr-Si coatings, 267, 2009, 1002-1008.

4. Jianliang Li, Dangsheng Xiong, Tribological behavior of graphite-containing nickel-based composite as function of temperature, load and counterface, 266, 2009, 360-367.

5. Khonsari M.M., Booser E.R., Applied Tribology, Jon Wiley \& Sons, Ltd., Chichaster 2008.

6. Kostornov A.G., Fushchich O.I., Chevychelova T.M., et al., Structural and phase transformations in the tribosynthesis area of copper-based selflubricating T. M. composite material, Powder Metall. Met. Ceram., 48 (5-6), 2009, 358-364.

7. Lenik K., Pashechko M., Dziedzic K., Barszcz M., The surface self-organization in process friction and corrosion of composite materials, Archives of Materials Science and Engineering, 30 (1), 2008, 9-12.
8. Pashechko M.I, Golubetz V.M., Chernetz M.V., Preparation and friction resistance of eutectic coatings, Naukova Dumka, Kyiv, 1993.

9. Pashechko M., Dziedzic K., Barszcz M., Study of the structure and properties of wear-resistant eutectic Fe-Mn-C-B-Si-Ni-Cr coatings, Powder metallurgy and metal ceramics, 52(7-8), 2013, 469-476.

10. Pashechko M., Lenik K., Segregation of atoms of the eutectic alloy $\mathrm{Fe}-\mathrm{Mn}-\mathrm{C}-\mathrm{B}-\mathrm{Si}-\mathrm{Ni}-\mathrm{Cr}$ at friction wear, 267, 2009, 1301-1304.

11. Riviere J.C., Myhra S., Handbook of surface and interface analysis, CRC Taylor \& Francis Group, Boca Raton 2009.

12. Winkelman H., Badisch E., Kirchgabner M., Daninger H., Wear mechanisms at high temperatures, Part 1: Wear mechanisms of different Fe-based alloys at elevated temperatures, Tribology Letters, 2009, 155-166.

13. Xinhong Wang, Fang Hanb, Xuemei Liu, Shiyao $\mathrm{Qu}$, Zengda Zou, Microstructure and wear properties of the Fe-Ti-V-Mo-C hardfacing alloy, 265, 2008, 583-589.

14. Zhang Y., Shi Y., Microstructure and Wear Resistance of Welding Surfacing Layer of Fe-Cr-Ti$\mathrm{Nb}-\mathrm{V}-\mathrm{C}$ Alloy System, China Surface Engineering, 4, 2006, 40-42. 